OCCASIONAL VIEWPOINT

\title{
Monitoring target reduction in hepatic venous pressure gradient during pharmacological therapy of portal hypertension: a close look at the evidence
}

\author{
U Thalheimer, M Mela, D Patch, A K Burroughs
}

Gut 2004;53:143-148

Recurrent variceal bleeding is very frequent after variceal haemorrhage and pharmacological therapy is the first choice treatment. Recently, baseline and repeat measurements of hepatic venous pressure gradient (HVPG) have been considered necessary to optimally manage patients receiving pharmacological therapy so as to reduce the frequency of rebleeding. However, the clinical validity and applicability of monitoring for target HVPG reductions is not sufficiently proven and needs to be specifically evaluated in a prospective trial.

See end of article for authors' affiliations

Correspondence to Professor A K Burroughs, Hepatobiliary Medicine and Liver Transplant Unit Royal Free Hospital, Pond St, London NW3 2QG UK; Andrew.Burroughs@ royalfree.nhs.uk

Accepted for publication 22 August 2003

\begin{abstract}
SUMMARY
Recurrent variceal bleeding is very frequent after variceal haemorrhage unless secondary prevention with pharmacological or endoscopic therapy is used. Recently, baseline and repeat measurements of hepatic venous pressure gradient (HVPG) have been considered necessary to optimally manage patients receiving pharmacological therapy so as to reduce the frequency of rebleeding, by defining two targets: $\geqslant 20 \%$ reduction from baseline HVPG, and an absolute reduction to $\leqslant 12 \mathrm{~mm} \mathrm{Hg}$. Five key studies are identified which contain data related to this issue, which are different in their study populations as regards number of patients, proportion of alcoholics, and those with severe liver disease. Importantly, $17-65 \%$ of patients did not have a baseline and/or a repeat HVPG measurement, many because they rebled early (7-22\%), limiting the clinical applicability of HVPG measurement. These groups are excluded from evaluation in those studies where the relationship between reduction of rebleeding and haemodynamic targets is strongest. This important source of bias, as well as other contrasting data, make it difficult to interpret the prognostic significance of haemodynamic data and to propose their routine clinical use. In conclusion, the clinical validity and applicability of monitoring for target HVPG reductions is not sufficiently proven by these studies and needs to be specifically evaluated in a prospective trial.
\end{abstract}

\section{INTRODUCTION}

Pharmacological therapy is the first choice treatment for the prevention of variceal rebleeding as it is equivalent but less costly than sclerotherapy $^{12}$ and banding for both primary ${ }^{3}$ and secondary prophylaxis. ${ }^{4-6}$ In early studies ${ }^{1-3}$ non-selective beta blockade dosage was empirical (that is, to the maximum tolerated by the patient or to reduction of the resting pulse rate to $55 / \mathrm{min}$ ). However, the key issue is whether targeted reduction of portal pressure, which involves a baseline and a repeated hepatic venous pressure gradient measurement (HVPG), is necessary in routine clinical practice. It significantly adds to the cost of pharmacological therapy, it is not universally available, and several issues regarding its use are as yet not clear, ${ }^{7}$ despite it being recommended in two recent reviews. ${ }^{89}$ Moreover, the cost effectiveness of HVPG measurement has been questioned in primary prevention ${ }^{10}$ and, furthermore, HVPG is known to decrease with time even in some untreated patients. ${ }^{11}{ }^{12}$ Despite a recent paper on tailoring of drug therapy, ${ }^{13}$ only some of the above issues have been considered..$^{74}$

\section{THE KEY STUDIES}

There have been five major studies ${ }^{4}{ }^{15-17}$ and one smaller series published as a correspondence ${ }^{18}$ in the context of prevention of variceal rebleeding in which HVPG has been measured at baseline and at a subsequent time point (table 1). Their targeted end points were all the same following the first report. ${ }^{15}$ These were an absolute reduction in HVPG to $12 \mathrm{~mm} \mathrm{Hg}$ or less, or a $20 \%$ reduction or more in HVPG from baseline, and the occurrence of rebleeding from varices.

The main data of these five studies are summarised in tables $1-3$, with additional data from our own study. ${ }^{6}$

The study by Sacerdoti and colleagues $^{18}$ included only 11 cirrhotic patients treated with nadolol. Haemodynamic response, defined as a decrease in HVPG of only $\geqslant 12 \%$, was observed in $54 \%$ of patients at one month, of whom none rebled. Among non-responders, 80\% had rebleeding, the same proportion as in 11 untreated cirrhotic patients who served as controls.

\section{SIMILARITIES AND DIFFERENCES BETWEEN THE KEY STUDIES}

Superficially all of these studies appear similar but there are some marked differences between them, making the haemodynamic data difficult

Abbreviations: HVPG, hepatic venous pressure gradient 
Table 1 Key published studies of repeated hepatic venous pressure gradient (HVPG) measurement in the prevention of variceal rebleeding: total populations and haemodynamic responders (absolute numbers of patients in parentheses)

\begin{tabular}{|c|c|c|c|c|c|}
\hline & $\mathrm{Feu}^{15}$ & Villanueva ${ }^{16}$ & McCormick $^{17}$ & Villanueva $^{4}$ & Patch $^{6}$ \\
\hline Total No of patients & 83 & $43^{*}$ & 63 & $72 \dagger$ & $51 \ddagger$ \\
\hline $\begin{array}{l}\% \text { of patients with baseline HVPG } \\
\text { measured }\end{array}$ & $83 \%(69)$ & $100 \%(43)$ & $89 \%(56)$ & $100 \%(72)$ & $78 \%(40)$ \\
\hline $\begin{array}{l}\text { \% of patients with remeasurement of } \\
\text { HVPG }\end{array}$ & $83 \%(69)$ & $72 \%(31)$ & $71 \%(45) \S$ & $68 \%(49)$ & $35 \%(18)$ \\
\hline $\begin{array}{l}\text { Time of, or mean interval to, } \\
\text { remeasurement (months) }\end{array}$ & 3 & $3-4$ & 5.3 & $1-3$ & 2 \\
\hline Child class $C$ & $6 \%(4)$ & $16 \%(7)$ & $6 \%(4)$ & $19 \%(14)$ & $47 \%(24)$ \\
\hline Alcoholic aetiology & $59 \%(41)$ & $51 \%(25)$ & $70 \%(31)$ & $50 \%(43)$ & $63 \%(32)$ \\
\hline Follow up (months) (median [range]) & $28[1-69]^{\star *}$ & $18[4-36]$ & $\begin{array}{l}22^{* *} \text { responders, } \\
26^{* *} \text { non-responders }[0.1-60]\end{array}$ & $20[1-65]$ & $8[0.25-46]$ \\
\hline Patients with nitrates & 0 & $100 \%(43)$ & $68 \%(30)$ & $100 \%(72)$ & $41 \%(22)$ \\
\hline Baseline HVPG (mm Hg) (mean (SD)) & $18.3(3.6)$ & $17.7(3.4)$ & $\begin{array}{l}17.5(0.6) \text { responders } \\
18(1.0) \text { non responders }\end{array}$ & $19.9(3.5)$ & $18.3(4.9)$ \\
\hline Haemodynamic responders & $36 \%(25)$ & $45 \%(14)$ & $64 \%(28)$ & $51 \%(25)$ & $50 \%(9)$ \\
\hline $\begin{array}{l}\text { Rebleeding in patients with baseline } \\
\text { HVPG measurement }\end{array}$ & $36 \%(25)$ & $26 \%(11)$ & $37 \%(16)$ & $33 \%(24)$ & $37 \%(19)$ \\
\hline $\begin{array}{l}\text { Mortality in patients with baseline } \\
\text { HVPG measurement }\end{array}$ & $13 \%(9)$ & $9 \%(4)$ & $n / a$ & $32 \%(23)$ & $33 \%(17)$ \\
\hline \multicolumn{6}{|c|}{$\begin{array}{l}\text { *Initial cohort } 121 \text { patients, } 86 \text { of whom were included ( } 43 \text { for each treatment arm). } \\
\text { tInitial cohort } 233 \text { patients, } 144 \text { of whom were included ( } 72 \text { for each treatment arm). } \\
\text { flnitial cohort } 205 \text { patients, } 102 \text { of whom were included ( } 51 \text { for each treatment arm). } \\
\text { §Only } 44 \text { patients included in the study (one patient excluded because of low initial and repeat HVPG }(7 \mathrm{~mm} \mathrm{Hg}) \text { ). } \\
\text { - Calculated on the } 44 \text { included patients. } \\
{ }^{* *} \text { Mean (range). }\end{array}$} \\
\hline
\end{tabular}

to interpret, and raising questions as to their use as valid therapeutic targets for pressure reduction (tables 1, 2).

\section{Patients in whom no baseline HVPG measurement or remeasurement took place (table 2)}

Not all patients had HVPG measured and/or remeasured, and therefore in this subgroup responder/non-responder status could not be assessed, varying from $65 \%$ in the study of Patch and colleagues ${ }^{6}$ to $17 \%$ in that of Feu and colleagues. ${ }^{15}$ Importantly, the rebleeding rate among these patients varied from $17 \%^{4}{ }^{16}$ to $64 \% .^{15}$ However, the situation is more complex than one would expect. In Feu's study ${ }^{15}$ the rebleeding rate was higher than in the non-responder group, as was the case in Patch's study, ${ }^{6}$ while in McCormick's study ${ }^{17}$ it was approximately equivalent to the non-responder group. In the studies of Villanueva and colleagues, ${ }^{416}$ the rebleeding rate in patients in whom no repeat HVPG measurement took place was the same in both studies, being intermediate between the rebleeding rate in responders and non-responders in the first study ${ }^{16}$ - the expected outcomebut in the second study it was equivalent to the responders' rebleeding rates. ${ }^{4}$ This represents an important source of bias.

\section{Interval to remeasurement of HVPG}

One reason why remeasurement could not take place is that some patients rebled before the second haemodynamic measurement: "some" (that is, no number specified) in the Villanueva papers, ${ }^{4}{ }^{16} 7 \%$ in Feu and colleagues, ${ }^{15} 16 \%$ in McCormick and colleagues, ${ }^{17}$ and $22 \%$ in Patch and colleagues. ${ }^{6}$

"Clearly, if many patients rebleed very early, it greatly diminishes the clinical applicability of remeasuring HVPG"

This raises an issue of when to remeasure HVPG, ${ }^{14}$ as the intervals to remeasurement (table 1) were 1-3 months, ${ }^{4}$ 3 months, ${ }^{15}{ }^{16}$ a mean of 5.3 months, ${ }^{17}$ and a mean of 57 days. ${ }^{6}$ Overall, between $25 \%$ and $44 \%$ of rebleeders rebled

Table 2 Patients rebleeding in the key study populations of repeated hepatic venous pressure gradient (HVPG) measurement in the pharmacological prevention of variceal rebleeding (absolute numbers in parentheses)

\begin{tabular}{|c|c|c|c|c|c|}
\hline & $\mathrm{Feu}^{15}$ & Villanueva ${ }^{16}$ & McCormick ${ }^{17}$ & Villanueva $^{4}$ & Patch $^{6}$ \\
\hline Total No of patients & 83 & $43^{*}$ & 63 & $72 \dagger$ & $51 \ddagger$ \\
\hline HVPG not measured & $17 \%(14)$ & $0 \%$ & $11 \%(7)$ & $0 \%$ & $22 \%(11)$ \\
\hline HVPG not remeasured & $17 \%(14)$ & $28 \%(12)$ & $17 \%(11) \S$ & $33 \%(23)$ & $65 \%(33)$ \\
\hline Rebleeding not remeasured & $64 \%(9 / 14)$ & $17 \%(2 / 12)$ & $28 \%(5 / 18)$ & $17 \%(4 / 23)$ & $33 \%(11 / 33)$ \\
\hline \multicolumn{6}{|l|}{ Rebleeding (patient groups) } \\
\hline Total & $36 \%(25 / 69)$ & $26 \%(11 / 43)$ & $37 \%(16 / 44)$ & $33 \%(24 / 72)$ & $37 \%(19 / 51)$ \\
\hline Haemodynamic responders & $8 \%(2 / 25)$ & $7 \%(1 / 14)$ & $43 \%(12 / 28)$ & $16 \%(4 / 25)$ & $11 \%(1 / 9)$ \\
\hline Haemodynamic non-responders & $52 \%(23 / 44)$ & $47 \%(8 / 17)$ & $25 \%(4 / 16)$ & $67 \%(16 / 24)$ & $22 \%(2 / 9)$ \\
\hline Repeat HVPG $\leqslant 12 \mathrm{~mm} \mathrm{Hg}$ & $0 \%(0 / 8)$ & $0 \%(0 / 9)$ & $30 \%(7 / 23)$ & $?(? / 7)$ & $50 \%(1 / 2)$ \\
\hline Rebleeding before remeasurement & $7 \%(5 / 69)$ & Some $e^{* *}$ & $16 \%(7 / 44)$ & Some $e^{\star *}$ & $22 \%(5 / 23)$ \\
\hline
\end{tabular}

*Initial cohort 121 patients, 86 of whom were included ( 43 for each treatment arm). tInitial cohort 233 patients, 144 of whom were included ( 72 for each treatment arm). flnitial cohort 205 patients, 102 of whom were included (51 for each treatment arm)

$\S$ Only 44 patients included in the study (one patient excluded because of low initial and repeat HVPG $(7 \mathrm{~mm} \mathrm{Hg})$ ).

- Rebleeding rate in both non-measured and non-remeasured patients (rebleeding occurred in two of seven patients who did not have their baseline HVPG measured and in three of 11 patients who did not have a repeat HVPG measurement).

**Number not stated (in the second study (Villanueva ${ }^{4}$ ) it can be derived that this number must be between 1 and 4). 
Table 3 Independent risk factors for variceal rebleeding in the key studies

\begin{tabular}{ll}
\hline Feu $^{15}$ & Absence of haemodynamic response \\
Villanueva $^{16}$ & $\begin{array}{l}\text { Sclerotherapy } v \text { drug treatment } \\
\text { HVPG at 3rd month }\end{array}$ \\
Villanueva $^{4}$ & $\begin{array}{l}\text { Endoscopic banding ligation } v \text { drug treatment } \\
\text { Absence of haemodynamic response } \\
\end{array}$ \\
& Child-Pugh score at 3rd month \\
Patch $^{6}$ & HVPG at baseline
\end{tabular}

HVPG, hepatic venous pressure gradient.

before remeasurement. Clearly, if many patients rebleed very early, it greatly diminishes the clinical applicability of remeasuring HVPG.

The proportion of haemodynamic responders in the drug arms of all studies varied between $36 \%{ }^{15}$ and $64 \% .{ }^{17}$ This variability could be influenced, and thus explained, by the time interval to the second HVPG measurement. The variability is not explained by the proportion of Child class C patients, although many may have rebled early, or by the baseline HVPG value or by mean drug dosage.

The lowest haemodynamic response rate was found by Feu and colleagues, ${ }^{15}$ perhaps because their patients did not receive nitrates. In McCormick's study, ${ }^{17}$ which had the highest haemodynamic response rate, $68 \%$ of patients had nitrates added (although the mean nitrate dose was about half that used in the Villanueva studies ${ }^{4}{ }^{16}$ ), yet there was also the longest time interval to remeasurement.

\section{Rates of rebleeding}

The overall rebleeding rates in those patients in whom HVPG was remeasured were very similar in the four studies, varying between $33 \%$ and 37\%, with the exception of the first Villanueva study ${ }^{16}$ which also used nitrates in which the rebleeding rate was $26 \%$. These data are consistent with the second study, ${ }^{4}$ which also used nitrates, because if one excludes the 12 patients who did not receive nadolol throughout (eight of them subsequently rebled) the rebleeding rate was $27 \%$. These lower rebleeding rates may be related to the shorter follow up in these two studies rather than to the use of nitrates because the other studies which also used nitrates ${ }^{6}{ }^{17}$ had higher rebleeding rates similar to that of Feu and colleagues ${ }^{15}$ in which only propranolol was used.

There was a higher rebleeding rate in cohorts with a higher proportion of alcoholic cirrhotics: from $26 \%$ in the first Villanueva study, ${ }^{16}$ which had the equal lowest percentage $(51 \%)$ of patients with alcoholic liver disease, to $37 \%$ in McCormick et al's study ${ }^{17}$ whose cohort has a $70 \%$ prevalence; if compliant with therapy and a target of $12 \mathrm{~mm} \mathrm{Hg}$ or less was reached, there was a low rebleeding rate $(9 \%)$.

\section{Relationship between rebleeding and haemodynamic response rate}

A cardinal point in comparing these studies is that no clear correlation exists between the haemodynamic response rate and rebleeding. Indeed, the study with the highest haemodynamic response rate $^{17}$ had the equal highest rebleeding rate $(37 \%)$, even though the percentage of patients in Child class $\mathrm{C}$ was only $6 \%$. Moreover, in the study of Feu and colleagues ${ }^{15}$ the rebleeding rate was similar to most of the other studies despite the lowest haemodynamic response rate and the longest follow up.

\section{"No clear correlation exists between the haemodynamic response rate and rebleeding"}

The rebleeding rate in haemodynamic responders varied widely between $7 \%$ and $43 \%$, and the rebleeding rate in non-responders between $22 \%$ and $67 \%$. This was mainly due to the study by McCormick and colleagues ${ }^{17}$ which reported a $43 \%$ rebleeding rate in responders and a $25 \%$ rebleeding rate in non-responders. Excluding the study by McCormick and colleagues, ${ }^{17}$ the rebleeding rate in haemodynamic responders varied from $7 \%$ to $16 \%$.

In the responder group, there was a trend for a lower rebleeding rate the earlier the response of HVPG was assessed (with a concurrent higher rebleeding rate in non-responders), especially if the small study by Sacerdoti and colleagues $^{18}$ with HVPG remeasurement at one month is considered. This could be due to the importance of an early decrease in HVPG as recurrent bleeding seems to be more frequent in the first weeks after the index bleed and HVPG tends to decrease with time, as mentioned previously. ${ }^{11}$ This would concur with the lack of correlation between responder status and rebleeding in the study by McCormick and colleagues $^{17}$ in which HVPG was remeasured at a mean of over five months. Conversely, there was a low incidence of recurrent bleeding in the non-responder group in the study of Patch and colleagues ${ }^{6}(22 \%)$ despite a median time of only 49 days to the second HVPG remeasurement. This could be due to the bias of exclusion of those patients who rebled before remeasurement.

There were lower rebleeding rates in non-responders in the studies with a higher percentage of alcoholic cirrhotics so that the relationship between responder status and rebleeding risk may be different in alcoholic cirrhotics compared with others. Abstinence may have a major influence on haemodynamic response and rebleeding rates, ${ }^{12}$ and conversely non-compliance may lead to more rebleeding. This may also explain the lack of relationship between haemodynamic response and rebleeding rates in McCormick's study ${ }^{17}$ (with the highest prevalence of alcoholic cirrhosis). These issues have not been adequately assessed in all of the studies.

\section{Influence of baseline HVPG}

Interpretation of the prognostic value of baseline HVPG could be affected by excluding patients who rebleed before remeasurement. This was not the case in the study by Patch and colleagues ${ }^{6}$ in which several patients who rebled did so before remeasurement but were not excluded from the evaluation of baseline HVPG. Indeed, only in this study was baseline HVPG reported to be predictive of rebleeding while the other studies did not specifically comment on this.

An interesting comparison can be made in the two papers by Villanueva and colleagues ${ }^{4}{ }^{16}$ which were very similar with regard to the population studied, treatment given, schedule of haemodynamic measurements, and duration of follow up (table 1). The main difference between the studies was baseline HVPG, which was substantially higher in the second study (mean HVPG 19.9 (3.5) v 17.7 (3.4) mm Hg). This probably explains the higher mortality $(32 \% \vee 9 \%)$ in this study. Indeed, there is an increase in mortality with increasing HVPG in many studies in hepatology, ${ }^{19}$ including a study in which HVPG was measured at two days after bleeding. ${ }^{20}$ The higher mean baseline HVPG could also be an explanation for drug treatment only reducing rebleeding rates in Child A patients in the second Villanueva study ${ }^{4}$ while rebleeding rates were similar in all Child classes in the first study. ${ }^{16}$ In this first study, Child B and Child C patients could have benefited because their baseline HVPG was already lower. Moreover, in the second Villanueva study, ${ }^{4}$ six patients randomised did not start nadolol therapy because of contraindications and were only given isosorbide mononitrate, and another six patients stopped nadolol (two due to complications and four due to non-compliance). Of these 12 patients, eight rebled, which means that at least two and perhaps all six patients who had contraindications to nadolol 
rebled. Clearly, an intention to treat analysis is correct statistically but in the clinical interpretation of rebleeding, patients who had contraindications to nadolol, and therefore never had the drug administered, cannot be considered failures of drug therapy. Because it was not stated whether the six patients who suspended nadolol did or did not have a second haemodynamic measurement, it is again difficult to interpret the relationship between rebleeding and haemodynamic measurement.

\section{OTHER STUDIES}

In some of these, the definition of haemodynamic response was not defined ${ }^{21}$ or the percentage of haemodynamic responders and non-responders was not reported, ${ }^{22}$ and thus cannot be evaluated.

\section{"Early measurement of HVPG after bleeding within 48 hours correlates with early rebleeding"}

Early measurement of HVPG after bleeding within 48 hours correlates with early rebleeding. ${ }^{23}$ The prognostic value of a single HVPG measurement in patients with recent bleeding with respect to rebleeding has been assessed in five studies $^{6024-26}$; three ${ }^{202425}$ failed to show a correlation between HVPG and rebleeding in contrast with the other two. ${ }^{62}$ Differences in timing of HVPG measurement make it difficult to compare these studies directly, again underscoring the need for standardisation before the prognostic value of this technique can be considered valid.

The acute HVPG response to a single oral dose of propranolol did not predict rebleeding in 77 patients. ${ }^{24} \mathrm{~A}$ study $^{27}$ of a single intravenous dose of propranolol (33 patients) did not report rebleeding in non-responders so that it is impossible to assess.

Two other studies ${ }^{1328}$ have also considered the importance of haemodynamic monitoring for preventing variceal bleeding during drug therapy, but their study populations comprised combined groups with and without a history of prior variceal haemorrhage, and thus cannot be readily compared with the key studies discussed above. Indeed, there seems to be a difference in haemodynamic response in patients receiving pharmacological therapy for primary compared with secondary prevention of variceal bleeding, ${ }^{13}{ }_{27}$ as well as very different risks of bleeding. In patients without varices, HVPG reduction after beta blockade is greater than that in those with varices. ${ }^{29}$ Populations of primary and secondary prevention should be kept apart when evaluating study results.

\section{"There seems to be a difference in haemodynamic response in patients receiving pharmacological therapy for primary compared with secondary prevention of variceal bleeding"}

A recent study ${ }^{30}$ found that a lack of haemodynamic response during drug therapy for secondary prevention of variceal bleeding was associated not only with rebleeding but also with development of ascites, spontaneous bacterial peritonitis, hepatorenal syndrome, and hepatic encephalopathy, as well as with a tendency to reduced survival, but it is unclear if there was a concomitant improvement in liver function.

Fewer data exist for monitoring target reduction of HVPG in primary prophylaxis. ${ }^{1131}$ Merkel and colleagues ${ }^{31}$ found that variceal bleeding was significantly more likely in poor responders while there was no significant difference in baseline HVPG between bleeders and non-bleeders; none of the patients with a HVPG $\leqslant 12 \mathrm{~mm} \mathrm{Hg}$ suffered a haemorrhage.
Groszmann and colleagues ${ }^{11}$ found that no patient who achieved a HVPG of $\leqslant 12 \mathrm{~mm} \mathrm{Hg}$ during subsequent measurements experienced a haemorrhage. When propranolol was withdrawn, the risk of variceal haemorrhage returned to what would be expected in an untreated population so that lifelong therapy is needed. ${ }^{32}$

\section{PRECISION OF HVPG MEASUREMENT}

A recent report comprising 102 patients $^{33}$ suggested that HVPG measurement itself may not be as reliable as previously thought $^{34-41}$ as $61 \%$ had a difference of between 4 and $34 \mathrm{~mm} \mathrm{Hg}$ in HVPG measurement in two separate hepatic veins. If a $4 \mathrm{~mm} \mathrm{Hg}$ difference in HVPG is considered, when baseline HVPG is $20 \mathrm{~mm} \mathrm{Hg}$, this already produces a $20 \%$ change. Thus defining a haemodynamic response by a percentage HVPG decrease of this magnitude, such as in this example, could be flawed due to the variability in measurement. However, in practice, the same hepatic vein is usually cannulated but nevertheless even when considering an intrasubject variation of $1-2 \mathrm{~mm} \mathrm{Hg}$, which is commonly acknowledged, ${ }^{19}$ this can make a difference in considering whether a patient is above or below $12 \mathrm{~mm} \mathrm{Hg}$ or achieves a decrease of more or less than $20 \%$ from baseline. It is self evident that it is much easier to achieve a $20 \%$ decrease, with a lower HVPG baseline value; the lower rebleeding rate in patients with $a \geqslant 20 \%$ decrease may indeed be correlated with a lower baseline HVPG value, as was the case in two of the studies. ${ }^{626}$

\section{DISCUSSION}

Detailed evaluation of the key studies showed great heterogeneity in the data. In particular, the patient populations were different in the proportion of alcoholic patients and those with severe liver disease. Baseline HVPG and the interval to remeasurement were also very variable, which obviously can lead to different proportions of patients achieving the target reductions of $\geqslant 20 \%$ reduction in HVPG from baseline and $\leqslant 12 \mathrm{~mm} \mathrm{Hg}$ absolute reduction. In addition, there is a spontaneous reduction in HVPG with time, ${ }^{11}{ }^{12}$ particularly in alcoholics ${ }^{12}$ who abstain. ${ }^{42}$ Lastly, the use of combination therapy, particularly nitrates, and perhaps spironolactone (not detailed in all studies, although ascitic patients are included), could affect the proportion of responders and rebleeders. ${ }^{43-46}$ The error in measurement ${ }^{33}$ may come into play, particularly if patients with lower pressures are being considered.

\section{"We view the current data as insufficient evidence to support monitoring the targeted reduction of HVPG in routine clinical practice"}

Therefore, the haemodynamic targets themselves, whether or not achieved by combination therapy or whenever achieved in time from the index bleeding episode, cannot be considered robust and clinically applicable. We view the current data as insufficient evidence to support monitoring the targeted reduction of HVPG in routine clinical practice, as is now recommended. ${ }^{8}$ 9

Firstly, the bias introduced due to rebleeding before remeasurement of HVPG in some patients and failure to remeasure HVPG in all patients makes it very difficult to be certain of the haemodynamic thresholds.

The interval to remeasurement is of undeniable importance. ${ }^{9}{ }^{47}$ The known reduction of HVPG with time after variceal bleeding makes it difficult to compare studies. Failure to achieve the haemodynamic target without rebleeding may be very relevant clinically. If after a long period the patient has not rebled, despite not achieving the haemodynamic targets, this may mean that for this particular patient 
the likelihood of rebleeding is far less. This needs to be studied.

It is possible that for the predictive assessment of pressure measurement in response to medical treatment for the prevention of variceal rebleeding, the baseline HVPG value could be of even greater importance than the haemodynamic response. The decrease in HVPG by $\geqslant 20 \%$ or to $\leqslant 12 \mathrm{~mm} \mathrm{Hg}$ may be an expression of a lower baseline HVPG value. This could be especially true if those patients who rebleed early, and thus cannot have a remeasurement, have a higher baseline HVPG.

Combination therapy with nitrates increases the percentage of haemodynamic responders, ${ }^{48}$ as assessed by HVPG, but its increased therapeutic efficacy compared with a nonselective beta blocker on its own in randomised clinical trials for preventing rebleeding is not established, with two studies coming to opposite conclusions. ${ }^{49} 50$

Do haemodynamic targets have prognostic value? There is little doubt that if one considers cohorts of patients, HVPG is indeed correlated with the risk of variceal bleeding, and that theoretically, target reduction could be of some use in evaluating the response during drug therapy. However, the evidence for the 20\% HVPG decrease from baseline as an appropriate target reduction seems to be of questionable value due to the biases illustrated in the studies. In contrast, decrease in HVPG to a value of $12 \mathrm{~mm} \mathrm{Hg}$ does seem to be of prognostic significance in the majority of studies, but as it only identifies a small percentage of patients (12-48\%, median $14 \%)^{4} 6^{15-17}$ it makes HVPG measurement and remeasurement of little clinical applicability.

"Logically, one should use target reduction in HVPG as a means of identifying patients who are less likely to bleed while complying with their given therapy"

Logically, one should use target reduction in HVPG as a means of identifying patients who are less likely to bleed while complying with their given therapy, and for those who do not achieve these targets, to offer them alternative therapy that will reduce their risk of rebleeding and improve survival. Ultimately, the only means of assessing the clinical utility of evaluating the haemodynamic response in patients given drug therapy for secondary prophylaxis of variceal bleeding would be a trial in which there would be four groups: one without HVPG measurement, and the other three groups in which HVPG measurements were performed. These three groups would be identified by randomisation at the second HVPG measurement so that haemodynamic non-responders would be randomised, either to continuation of drug therapy or to an alternative treatment such as endoscopic banding ligation with or without drugs. The remaining group would be the haemodynamic responders. In such a study an appropriate time interval which is clinically applicable for the repeat measurement would need to be defined a priori, perhaps as short as two weeks from the index bleeding episode.

\section{Authors' affiliations}

U Thalheimer, M Mela, D Patch, A K Burroughs, Liver Transplantation and Hepatobiliary Unit, Royal Free Hospital, Pond St, London NW3 2QG, UK

\section{REFERENCES}

1 D'Amico G, Pagliaro L, Bosch J. The treatment of portal hypertension: a metaanalytic review. Hepatology 1995;22:332-54.

2 Defranchis R, Primignani $M$. Endoscopic treatment for portal hypertension. Semin Liver Dis 1999;19:439-55.
3 Imperiale TF, Chalasani N. A meta-analysis of endoscopic variceal ligation fot primary prophylaxis of esophageal bleeding. Hepatology 2000;33:1003-4.

4 Villanueva C, Minana J, Ortiz J, et al. Endoscopic ligation compared with combined treatment with nadolol and isosorbide mononitrate to prevent recurrent variceal bleeding. N Engl J Med 2001;345:647-55.

5 Lo G-H, Chen W-C, Chen M-H, et al. Banding ligation versus nadolol and isosorbide mononitrate for the prevention of esophageal variceal rebleeding. Gastroenterology 2002;123:728-34.

6 Patch D, Sabin CA, Goulis J, et al. A randomized, controlled trial of medical therapy versus endoscopic ligation for the prevention of variceal rebleeding in patients with cirrhosis. Gastroenterology 2002; 123:1013-19.

7 Bosch J. A la carte or menu fixe: improving pharmacologic therapy of portal hypertension. Hepatology 2002;36:1330-2.

8 Bosch J, Abraldes JG, Groszmann R. Current management of portal hypertension. J Hepatol 2003;38(suppl 1):S54-68.

9 Bosch J, García-Pagán JC. Prevention of variceal bleeding. Lancet 2003:361:952-4

10 Hicken BL, Sharara Al, Abrams GA, et al. Hepatic venous pressure gradient measurements to assess response to primary prophylaxis in patients with cirrhosis: a decision analytical study. Aliment Pharmacol Ther 2003; 17: 145-53.

11 Groszmann RJ, Bosch J, Grace ND, et al. Hemodynamic events in a prospective randomized trial of propranolol versus placebo in the prevention of a first variceal hemorrhage. Gastroenterology 1990;99:1401-7.

12 Vorobioff J, Groszmann RJ, Pibacea E, et al. Prognostic value of hepatic venous pressure gradient measurements in alcoholic cirrhosis: a 10-year prospective study. Gastroenterology 1996;111:701-9.

13 Bureau C, Péron JM, Alric L, et al. "A la carte" treatment of portal hypertension: adapting medical therapy to hemodynamic response for the prevention of bleeding. Hepatology 2002;36:1361-6.

14 Groszmann RJ, Garcia-Tsao G. Endoscopic variceal banding vs. pharmacological therapy for the prevention of recurrent variceal haemorrhage: what makes the difference, Gastroenterology 2002;123:1388-91.

15 Feu F, Garcia-Pagan JC, Bosch J, et al. Relation between portal pressure response to pharmacotherapy and risk of recurrent variceal haemorrhage in patients with cirrhosis. Lancet 1995;346:1056-9.

16 Villanueva C, Balanzo J, Novella MT, et al. Nadolol plus isosorbide mononitrate compared with sclerotherapy for the prevention of variceal rebleeding. N Engl J Med 1996;334:1624-9.

17 McCormick PA, Patch D, Greenslade L, et al. Clinical vs hemodynamic response to drugs in portal hypertension. J Hepatol 1998;28:1015-19.

18 Sacerdoti D, Merkel C, Gatta A. Importance of the 1-month-effect of nadolol on portal pressure in predicting failure of prevention of rebleeding in cirrhosis. $J$ Hepatol 1991; 12:124-5.

19 Armonis A, Patch D, Burroughs AK. Hepatic venous pressure measurement: an old test as a new prognostic marker in cirrhosis? Hepatology 1997:25:245-8.

20 Vinel JP, Cassigneul J, Levade M, et al. Assessment of short-term prognosis after variceal bleeding in patients with alcoholic cirrhosis by early measurement of portohepatic gradient. Hepatology 1986:6:116-17.

21 Burroughs AK, Jenkins WJ, Sherlock S, et al. Controlled trial of propranolol for the prevention of recurrent variceal hemorrhage in patients with cirrhosis. N Engl J Med 1983;309:1539-42.

22 Escorsell A, Bañares R, García-Pagán JC, et al. TIPS versus drug therapy in preventing variceal rebleeding in advanced cirrhosis: a randomized controlled trial. Hepatology 2002;35:385-92.

23 Moitinho E, Escorsell A, Bandi JC, et al. Prognostic value of early measurements of portal pressure in acute variceal bleeding. Gastroenterology 1999;117:626-31.

24 Valla D, Jiron MI, Poynard T, et al. Failure of haemodynamic measurements to predict recurrent gastrointestinal bleeding in cirrhotic patients receiving propranolol. J Hepatol 1987;5:144-8.

25 Patch D, Armonis A, Sabin K, et al. Single portal pressure measurement predicts survival in cirrhotic patients with recent bleeding. Gut 1999;44:264-9.

26 Vlavianos P, Gimson ES, Hayllar K, et al. Prognostic significance of systemic and portal haemodynamic parameters in patients with cirrhosis and previous variceal bleeding. Gut 1990;31:592A.

27 De BK, Sen S, Biswas PK, et al. Propranolol in primary and secondary prophylaxis of variceal bleeding among cirrhotics in India: a hemodynamic evaluation. Am J Gastroenterol 2000;95:2023-8.

28 Escorsell A, Bordas JM, Castañeda B, et al. Predictive value of the variceal pressure response to continued pharmacological therapy in patients with cirrhosis and portal hypertension. Hepatology 2000;31:1061-7.

29 Escorsell A, Ferayorni L, Bosch J, et al. The portal pressure response to $\beta$ blockade is greater in cirrhotic patients without varices than in those with varices. Gastroenterology 1997;112:2012-16.

30 Abraldes JG, Tarantino I, Turnes J, et al. Hemodynamic response to pharmacological treatment of portal hypertension and long-term prognosis of cirrhosis. Hepatology 2003;37:902-8.

31 Merkel C, Bolognesi M, Sacerdoti D, et al. The hemodynamic response to medical treatment of portal hypertension as a predictor of clinical effectiveness in the primary prophylaxis of variceal bleeding in cirrhosis. Hepatology 2000;32:930-4.

32 Abraczinskas DR, Ookubo R, Grace ND, et al. Propranolol for the prevention of first esophageal variceal hemorrhage: a lifetime commitment? Hepatology 2001;34:1096-102.

33 Keiding S, Vilstrup $\mathrm{H}$. Intrahepatic heterogeneity of hepatic venous pressure gradient in human cirrhosis. Scand J Gastroenterol 2002;37:960-4. 
34 Rector WG. Propranolol for portal hypertension. Evaluation of therapeutic response by direct measurement of portal vein pressure. Arch Intern Med $1985 ; 145: 648-50$

35 Viallet A, Joly JG, Marleau D, et al. Comparison of free portal venous pressure and wedged hepatic venous pressure in patients with cirrhosis of the iver. Gastroenterology 1970;59:372-5

36 Iwao T, Toyonaga A, Ikegami $M$, et al. Wedged hepatic venous pressure reflects portal venous pressure during vasoactive drug administration in nonalcoholic cirrhosis. Dig Dis Sci 1994;39:2439-44.

37 Perelló A, Escorsell A, Bru C, et al. Wedged hepatic venous pressure adequately reflects portal pressure in hepatitis $C$ virus-related cirrhosis. Hepatology 1999;30:1393-7.

38 Boyer TD, Triger DR, Horisawa M, et al. Direct transhepatic measurement of portal vein pressure using a thin needle. Comparison with wedged hepatic vein pressure. Gastroenterology 1977:72:584-9.

39 Groszmann RJ, Glickman M, Blei AT, et al. Wedged and free hepatic venous pressure measured with a balloon catheter. Gastroenterology 1979:76:253-8.

40 Lin HC, Tsai YT, Lee FY, et al. Comparison between portal vein pressure and wedged hepatic vein pressure in hepatitis B-related cirrhosis. J Hepatol 1989;9:326-30.

41 Reynolds TB, Ito S, Iwatsuki S. Measurement of portal pressure and its clinical application. Am J Med 1970:49:649-57.

42 Reynolds TB, Geller HM, Kuzma OT, et al. Spontaneous decrease in portal pressure with clinical improvement in cirrhosis. N Engl J Med 1960;263:734-9
43 Okumura H, Arakami T, Katsuta Y, et al. Reduction in hepatic venous pressure gradient as a consequence of volume contraction due to chronic administration of spironolactone in patients with cirrhosis and no ascites. Am J Gastroenterol 1991;86:46-52.

44 García-Pagán J, Salmeron J, Feu F, et al. Effects of low-sodium diet and spironolactone on portal pressure in patients with compensated cirrhosis. Hepatology 1994; 19:1095-9.

45 Sugano S, Kawafune T, Okajima T, et al. Chronic splanchnic hemodynamic effects of spironolactone with unrestricted sodium diet in patients with compensated cirrhosis. Dig Dis Sci 1998:43:893-7.

46 Nevens $F$, Lijnen $P$, VanBilloen $H$, et al. The effect of long-term treatment with spironolactone on variceal pressure in patients with portal hypertension without ascites. Hepatology 1996;23:1047-52.

47 Thalheimer U, Mela M, Patch D, et al. Prevention of variceal rebleeding Lancet 2003:361:2244-5.

48 Garcia-Pagan JC, Feu F, Bosch J, et al. Propranolol compared with propranolol plus isosorbide-5-mononitrate for portal hypertension in cirrhosis. A randomized controlled study. Ann Intern Med $1991 ; 114: 869-73$

49 Gournay J, Masliah C, Martin T, et al. Isosorbide mononitrate and propranolol compared with propranolol alone for the prevention of variceal rebleeding. Hepatology 2000;31:1239-45.

50 Patti R, D'Amico G, Pasta L, et al. Isosorbide mononitrate (IMN) with nadolol compared to nadolol alone for prevention of recurrent bleeding in cirrhosis. A double-blind placebo-controlled randomised trial. $J$ Hepatol 1999;30(suppl 1):81A.

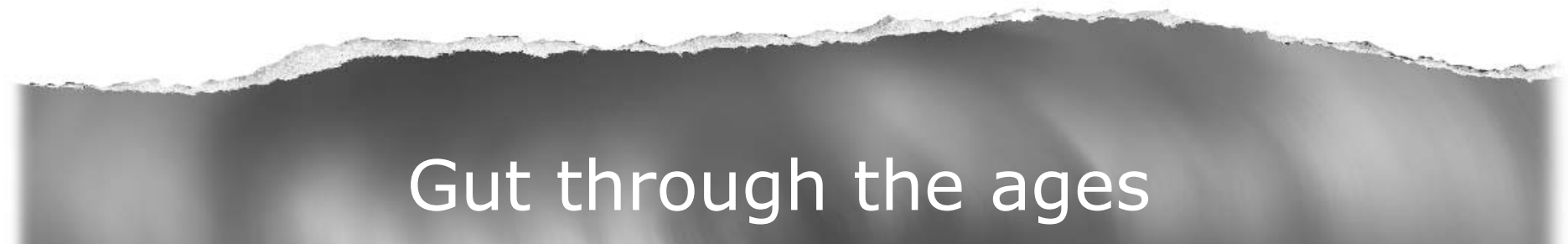

Browse the Archive

Gut online has an archive of content dating back to 1966.

Full text from 1997; abstracts from 1975; table of contents from 1966

\section{www.gutjnl.com}

